\title{
On the evolution of local material properties and residual stress in a three-pass SA508 steel weld
}

\author{
A.F. Mark ${ }^{\text {a,* }}$, J.A. Francis ${ }^{\text {b }}$, H. Dai ${ }^{\text {a }}$, M. Turski ${ }^{\text {a }}$, P.R. Hurrell ${ }^{\text {c }}$, S.K. Bate ${ }^{\text {, }}$, \\ J.R. Kornmeier ${ }^{\mathrm{e}}$, P.J. Withers ${ }^{\mathrm{a}}$ \\ ${ }^{a}$ School of Materials, The University of Manchester, Manchester M13 9PL, UK \\ ${ }^{\mathrm{b}}$ School of Mechanical, Aerospace and Civil Engineering, The University of Manchester, Manchester M13 9PL, UK \\ ${ }^{\mathrm{c}}$ Rolls-Royce plc, Raynesway, Derby DE21 $7 X X, U K$ \\ ${ }^{\mathrm{d}}$ Serco Technical Services, Birchwood Park, Warrington, Cheshire WA3 6GA, UK \\ ${ }^{\mathrm{e}}$ FRM-II, Technische Universität München, D-85747 Garching, Germany
}

Received 23 February 2012; received in revised form 8 March 2012; accepted 9 March 2012

\begin{abstract}
In multi-pass welds, the development of residual stress generally depends on the response of the weld metal, heat-affected zone (HAZ) and nearby parent material to complex thermo-mechanical cycles. Here, the evolution of local material properties and residual stress was investigated for each of these zones during the manufacture of a three-pass groove weld in SA508 steel. Residual stress distributions were measured by neutron diffraction for a sample in which only one weld bead had been deposited, and again for a completed three-pass weld. The evolution of material properties was also characterised by measuring local hardness and conducting tensile tests on small coupons that were extracted from the same welded specimens. Overall, the addition of subsequent weld passes resulted in lower peak tensile residual stresses in the weld as a whole, softening of the HAZ, modest cyclic hardening in nearby parent metal, and some softening in the low-carbon weld metal.
\end{abstract}

(C) 2012 Acta Materialia Inc. Published by Elsevier Ltd. All rights reserved.

Keywords: Annealing; Cyclic response; Martensitic phase transformation; Structural integrity; Thermo-mechanical processing

\section{Introduction}

Both the performance and the safe operation of a thermal power plant are highly dependent on the integrity of its welded joints. Indeed, many critical components, such as the header and main steam pipe in a fossil-fired plant, or the reactor pressure vessel in a pressurised water reactor, are joined by fusion welding. The localised melting that takes place during welding is in turn associated with rapid heating and cooling, the formation of microstructures that differ from the parent material, as well as the development of substantial residual stresses [1]. The latter are significant because they can be additive to externally applied (or

\footnotetext{
* Corresponding author.

E-mail address: alison.mark@manchester.ac.uk (A.F. Mark).
}

operational) loads and, as such, they can increase the driving force for fracture [2], while also accelerating the degradation of the material $[3,4]$.

In recent years significant efforts have been made to incorporate weld residual stresses into structural integrity assessments on power plant infrastructure. In the R6 assessment procedure [5], for example, there are three options for accounting for residual stress in welds. The first, and most conservative, approach is to assume that the residual stresses are uniform and of yield level magnitude across the joint. The second option introduces another level of sophistication by referring the assessor to a compendium of residual stress profiles and providing guidance on identifying an appropriate profile for assessment purposes. Finally, the third option involves the assessor undertaking a detailed analysis of the weld configuration through a combination 
of numerical modelling and carrying out residual stress measurements.

Numerical modelling is a vitally important tool in the power generation sector. However, any ability to predict residual stresses in thick-section multi-pass welds must be underpinned by an understanding of the way in which the material being joined will respond to the complex thermo-mechanical cycles that arise during welding. This is clearly pertinent in the case of welds in components made from austenitic stainless steels due to the manner in which these steels harden when subjected to multiple welding thermal cycles [6], and the fact that this hardening is associated with a corresponding capacity to sustain stress. Indeed, substantial efforts have been made to develop empirical models for the cyclic hardening of austenitic steels based on the concepts of isotropic and kinematic hardening, as well as models that use a combination of these concepts [7-10]. While there is some evidence to suggest that ferritic steels do not cyclically harden to the same extent [11], the situation with these steels is made more complex due to the influence of the solid-state phase transformations that occur on heating and cooling [12]. Phase transformations influence the properties of the material directly, as they will differ from one phase to another, but they also influence the development of stress because each type of transformation in ferritic steels has an associated transformation strain [13]. Indeed, a substantial body of work has been carried out that demonstrates that solidstate phase transformations can have a very large effect on residual stresses in ferritic steel welds [14-17].

In this paper, we report on a body of experimental work designed to provide insights into the evolution of both material properties and residual stress in an SA508 steel weld subjected to multiple passes. A simple three-pass weld configuration was chosen so that the outcomes might be of general interest and serve as a valuable test case for the validation of numerical modelling strategies. In this manner we have developed a much better understanding of multiple pass welding for SA508 steel and similar steels.

\section{Experiments}

\subsection{Welding}

Two plates were machined from a block of SA508 Grade 3 Class 1 steel to the dimensions of $200 \times 150 \times 20 \mathrm{~mm}^{3}$. A $6 \mathrm{~mm}$ deep groove was then machined along the centreline of the long axis on one face of each plate, as shown in Fig. 1. The machined plates were then stress relieved. The nominal chemical composition for the steel is listed in Table 1 while the mechanical properties for the steel in the quenched and tempered condition are given in Table 2.

The first plate specimen had a single weld bead deposited into the machined groove using the gas-tungsten arc welding process. Prior to welding, the plate was preheated to a temperature of $150{ }^{\circ} \mathrm{C}$. The weld bead was deposited using a low carbon steel filler wire (SD3), with a diameter of $1.2 \mathrm{~mm}$, for

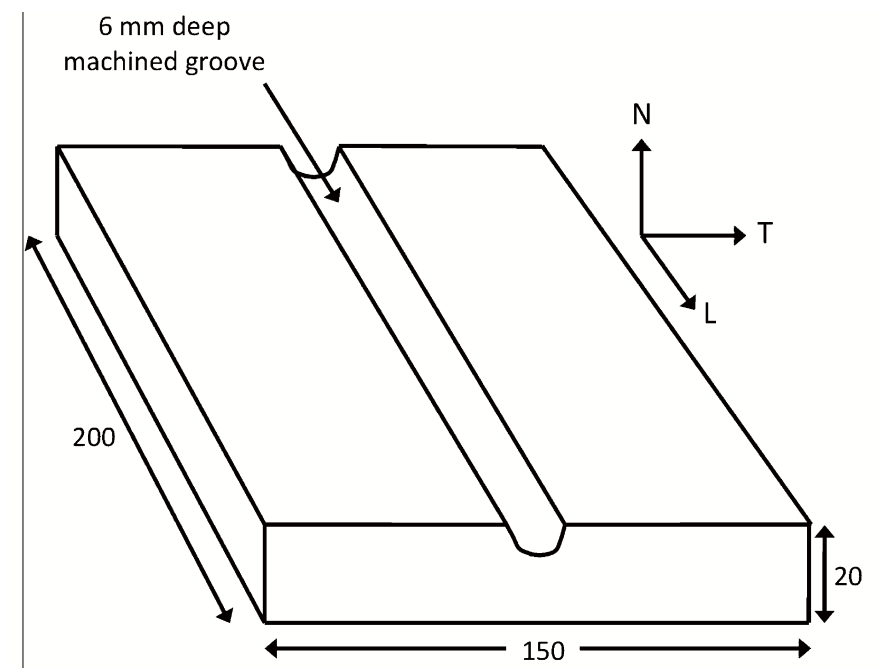

(a)

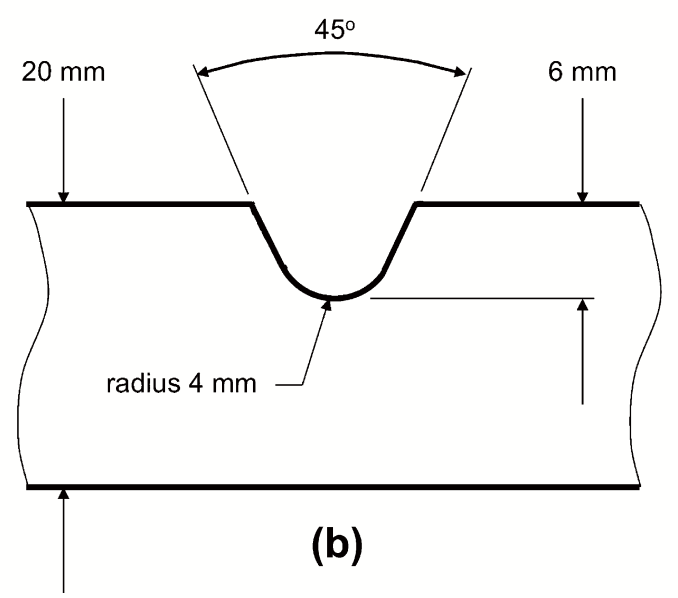

Fig. 1. Schematic representation of (a) the overall specimen configuration and (b) details of the weld groove geometry for the one-pass and threepass specimens. A coordinate system denoting longitudinal $(L)$, transverse $(T)$ and normal $(N)$ directions is also shown in (a). The welding direction is along the longitudinal direction.

which the nominal composition is given in Table 1. The weld bead was deposited using a nominal heat input of $2 \mathrm{~kJ} \mathrm{~mm}$ ${ }^{-1}$ and a welding speed of $76 \mathrm{~mm} \mathrm{~min}^{-1}$. The tungsten electrode contained $2 \%$ thoria, was $3.2 \mathrm{~mm}$ in diameter, and it was prepared so that it had a truncated conical tip with an included angle of $60^{\circ}$ and a $0.5 \mathrm{~mm}$ diameter flat end. Welding grade argon was used as the shielding gas.

The second plate was welded using the same nominal welding parameters as the first. The principal difference between the two samples was that, in the case of the second sample, a further two weld passes were deposited in order to completely fill the machined groove. The interpass temperature was nominally identical to the preheat temperature $\left(150^{\circ} \mathrm{C}\right)$.

\subsection{Neutron diffraction}

A $25 \mathrm{~mm}$ long slice of material was removed from the weld-start end of each plate after welding so that 
Table 1

Nominal compositions of SA508 Grade 3 Class 1 steel and SD3 weld filler metal (wt.\%).

\begin{tabular}{|c|c|c|c|c|c|c|c|c|c|c|c|}
\hline & $\mathrm{C}$ & $\mathrm{Si}$ & $\mathrm{Mn}$ & $\mathrm{Ni}$ & $\mathrm{Cr}$ & Mo & $\mathrm{V}$ & $\mathrm{Al}$ & $\mathrm{Cu}$ & $\mathrm{N}$ & $\mathrm{Fe}$ \\
\hline SA508 & 0.2 & 0.25 & 1.4 & 0.8 & 0.2 & 0.5 & 0.003 & 0.003 & 0.04 & $100 \mathrm{ppm}$ & $\overline{\text { Bal. }}$ \\
\hline SD3 & 0.08 & 0.3 & 1.4 & 0.03 & 0.04 & 0.01 & & & 0.04 & & Bal. \\
\hline
\end{tabular}

Table 2

Mechanical properties of SA508 Grade 3 Class 1 steel in the quenched and tempered condition [18].

\begin{tabular}{lll}
\hline $\begin{array}{l}0.2 \% \text { proof stress } \\
(\mathrm{MPa})\end{array}$ & $\begin{array}{l}\text { Ultimate tensile strength } \\
(\mathrm{MPa})\end{array}$ & $\begin{array}{l}\text { Elongation to failure } \\
(\%)\end{array}$ \\
\hline 450 & $560-600$ & 25 \\
\hline
\end{tabular}

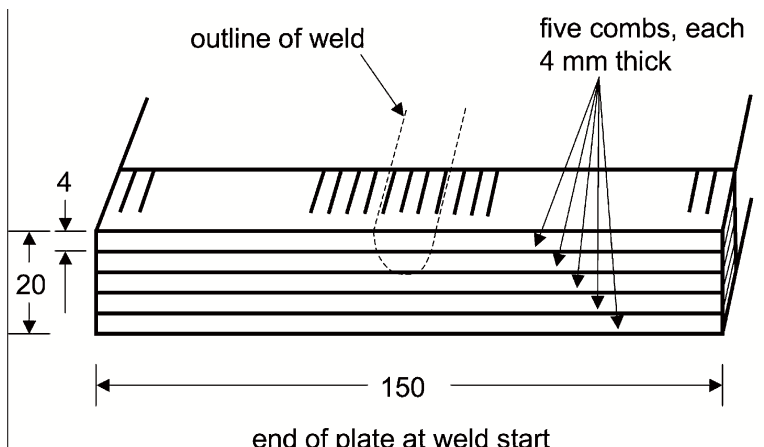

(a)

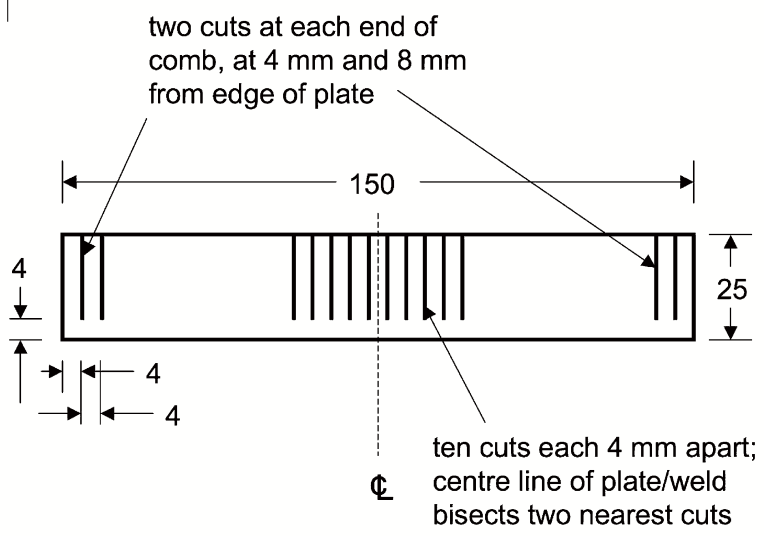

(b)

Fig. 2. Schematic showing (a) the location and orientation of the five strain-free reference $\left(d_{0}\right)$ combs, (b) the geometry (in $\mathrm{mm}$ ) of each comb.

comb-shaped strain-free reference $\left(d_{0}\right)$ specimens could be prepared. These specimens are required so that any stress-free changes in lattice parameter across the weld can be determined, as might occur due to gradients in solute concentration brought about by the welding cycle [19]. The configuration of the comb-shaped specimens is shown in Fig. 2. Note that five separate combs were prepared by electric discharge machining, each at a different depth, from within the $20 \mathrm{~mm}$ thick off-cut. As such, each comb was $\sim 4 \mathrm{~mm}$ thick and, within each comb, a number of teeth were formed by making further cuts. The crosssections of the individual comb teeth were nominally
$4 \times 4 \mathrm{~mm}^{2}$. It is assumed that any macroscopic residual stresses that originally existed within the slice as a consequence of welding will have been relaxed by the material removal.

The neutron diffraction measurements were made on the Stress-Spec strain scanning instrument at the FRM II neutron source in Garching, Germany. The $\left\{\begin{array}{lll}2 & 1 & 1\end{array}\right\}$ crystal reflection was used, and a nominal gauge volume of $2 \times 2 \times 2 \mathrm{~mm}^{3}$ was employed in all cases. The locations within the transverse section for which $d_{0}$ and $d$ were measured are indicated in Fig. 3. For $d_{0}$ the locations correspond to the locations of specific teeth in the reference combs and were measured $3 \mathrm{~mm}$ from the end of each tooth, where we would expect the relaxation of macroscopic stress to be most effective. Furthermore, care was taken to ensure that the gauge volume was always completely immersed within an individual comb tooth, so that errors associated with incomplete gauge filling could be avoided [20]. The corresponding $d$-spacing map was obtained over the transverse section at the mid-length of the weld, where it is believed that the residual stresses will not have been significantly influenced by the removal, for the cutting the reference combs, of a $25 \mathrm{~mm}$ thick slice at the weld-start end of each sample. In total, measurements were made at 45 locations within the one-pass specimen and 53 locations within the three-pass specimen.

In calculating elastic strains and stresses at the midlength position of the weld, it was assumed that the values measured for $d_{0}$ would have been identical if they had been measured at the mid-length position of the specimen. Accordingly, the longitudinal strain acting at each point $(x, y)$ on the mid-length measurement plane, designated as $\varepsilon_{L(x, y)}$, was calculated as follows:

$\varepsilon_{L(x, y)}=\frac{d_{L(x, y)}-d_{0(x, y)}}{d_{0(x, y)}}$

where $d_{L(x, y)}$ is the value of the $d$-spacing that was measured in the longitudinal orientation at point $(x, y)$. In this way, the strains acting in the longitudinal (L), transverse $(\mathrm{T})$ and normal $(\mathrm{N})$ directions (with the orientations as defined in Fig. 1a) were evaluated at each point $(x, y)$ in the measurement plane. The stress acting in the longitudinal orientation, for example, at a point $(x, y)$ in the measurement plane, which is denoted by $\sigma_{L(x, y)}$, can then be calculated using a generalised version of Hooke's law according to the following equation:

$$
\sigma_{L(x, y)}=\frac{E_{\{211\}}}{1+v_{\{211\}}}\left[\varepsilon_{L(x, y)}+\frac{v_{\{211\}}}{1-2 v_{\{211\}}}\left(\varepsilon_{L(x, y)}+\varepsilon_{T(x, y)}+\varepsilon_{N(x, y)}\right)\right]
$$




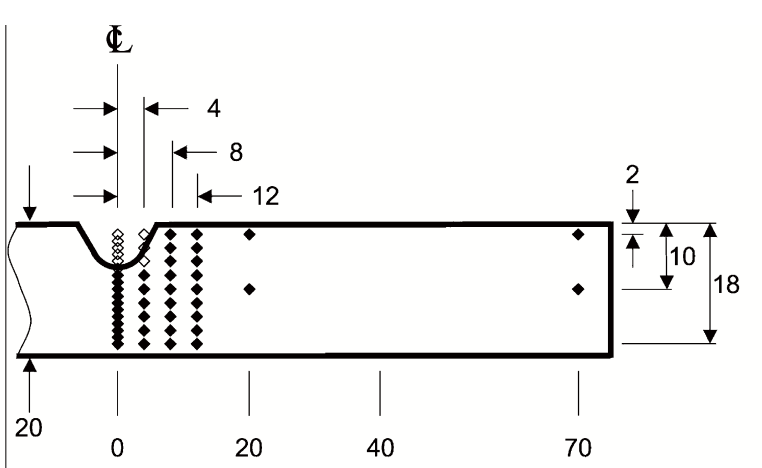

(a)

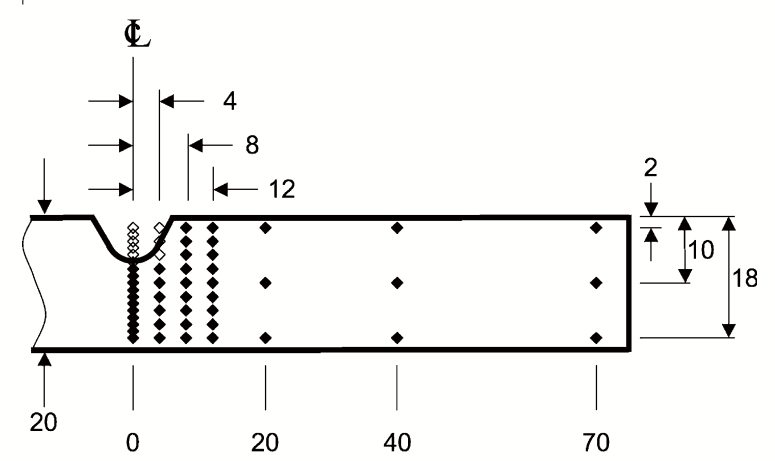

(b)

Fig. 3. Schematic representation of locations of neutron diffraction measurements for (a) stress-free lattice parameters and (b) residual strain. The solid points were measured in both welded specimens, whereas the open points could only be measured in the three-pass specimen. The nominal neutron diffraction gauge volume was $2 \times 2 \times 2 \mathrm{~mm}^{3}$. All dimensions in $\mathrm{mm}$.

where $E_{\{211\}}$ and $v_{\{211\}}$ are, respectively, the $\left\{\begin{array}{lll}2 & 1 & 1\end{array}\right\}$ planespecific values of the elastic modulus and Poisson's ratio, determined from in situ tensile diffraction data. Here $E_{\{211\}}$ and $v_{\{211\}}$ were taken to be $216 \mathrm{GPa}$ and 0.27 , respectively, following Daymond and Priesmeyer [21].

\subsection{Hardness}

Sections for hardness testing were cut from the start end of each welded plate after neutron diffraction measurements had been performed. Slices $\sim 8 \mathrm{~mm}$ thick were cut, polished to a $0.25 \mu \mathrm{m}$ finish, and then etched by immersion with agitation in $2 \%$ Nital for $10 \mathrm{~s}$ to reveal the microstructure. Hardness testing was then carried out on an Instron/ Wilson Tukon 2100 hardness testing machine, with a $0.5 \mathrm{~kg}$ load and a Vickers indenter. An initial traverse was made, with measurements every $0.25 \mathrm{~mm}$ down the weld centre line (WCL), starting $0.23 \mathrm{~mm}$ below the surface of the weld bead and finishing $4 \mathrm{~mm}$ from the bottom surface of the plate. A second traverse was made perpendicularly to the first traverse with measurements at intervals of $0.25 \mathrm{~mm}$ along a line $1.3 \mathrm{~mm}$ (three-pass specimen) or $4.5 \mathrm{~mm}$ (one-pass specimen) below the top surface of the plate, starting at the WCL and extending $11 \mathrm{~mm}$. These lines were selected so that they traversed approximately the same distance of weld filler metal and heat-affected zone (HAZ) in both specimens.

\subsection{Mechanical testing}

Tensile specimens having the dimensions shown in the inset to Fig. 4 were cut from the welded plates using electric discharge machining, after the slices for hardness testing had been removed. The long axis of the specimens was aligned with the welding direction and ran along the centre of the weld. The specimens were cut in a stack so that each one was extracted from a different weld depth. A sketch of the cutting layout is shown in Fig. 4. The top and bottom specimens in the stack from each weld plate were not of the required thickness and so were not used for tensile tests. Tables 3 and 4 list the weld region associated with each tested specimen for the one- and three-pass specimens respectively. The arrangement resulted in six tensile specimens for the one-pass weld specimen and eight tensile specimens for the three-pass weld specimen.

The tensile tests were performed on an Instron 5569 testing machine configured with a $10 \mathrm{kN}$ load cell. An extension rate of $1 \mathrm{~mm} \mathrm{~min}{ }^{-1}$ was used and the specimens were loaded to failure. Strain gauges (Vishay General Purpose Strain Gauges $1.57 \mathrm{~mm}$ wide by $2.9 \mathrm{~mm}$ long), glued to the gauge region of the specimens prior to testing, were used to measure strain during the tests. A National Instruments system with Signal Express software was used to gather and convert the data from the strain gauges.

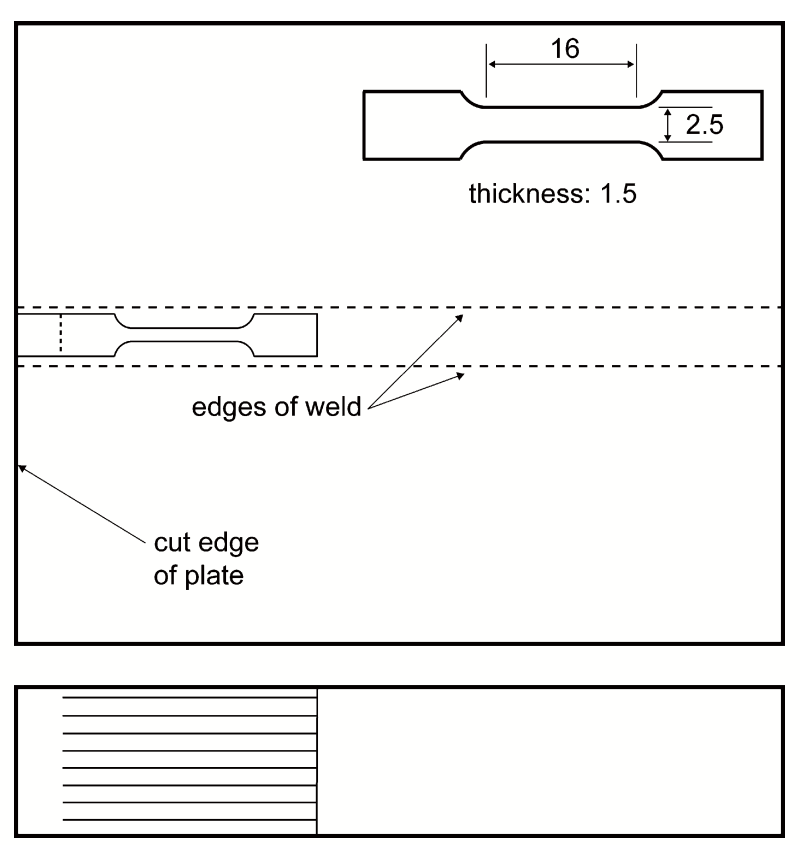

Fig. 4. Cutting layout for tensile specimens within the welded plates. Specimens were cut in a stack with a backbone attached so the depth of each specimen within the welded plate was known. The specimens were cut from the backbone and individually labelled before testing. Figure is not to scale. 
Table 3

Details of specimens for tensile tests from one-pass weld specimen.

\begin{tabular}{lll}
\hline Specimen no. & $\begin{array}{l}\text { Depth from weld surface } \\
\text { (relative to surface of } \\
\text { three-pass weld) }(\mathrm{mm})\end{array}$ & Weld region \\
\hline 2 & $3.2(7.2)$ & Weld metal 1 \\
3 & $4.9(8.9)$ & Fine-grained HAZ ${ }^{\mathrm{a}} 1$ \\
4 & $6.7(10.7)$ & Intercritical HAZ 1 \\
5 & $8.6(12.6)$ & Parent metal, close \\
6 & $10.5(14.5)$ & Parent metal, middle \\
7 & $12.4(16.4)$ & Parent metal, far \\
\hline${ }^{\mathrm{a}} 1$ 1- from first pass. & \\
${ }^{\mathrm{b}}$ HAZ - heat-affected zone. &
\end{tabular}

Table 4

Details of specimens for tensile tests from three-pass weld specimen.

\begin{tabular}{lll}
\hline Specimen no. & $\begin{array}{l}\text { Depth from weld } \\
\text { surface }(\mathrm{mm})\end{array}$ & Weld region \\
\hline 2 & 2.0 & Weld metal 3 \\
3 & 3.9 & Course-grained HAZ 3 \\
4 & 5.8 & Fine-grained HAZ 3 \\
5 & 7.6 & Course-grained HAZ 1,3 \\
6 & 9.4 & Fine-grained HAZ 1,3 \\
7 & 11.2 & Parent metal, close \\
8 & 13.1 & Parent metal, middle \\
9 & 15.0 & Parent metal, far \\
\hline
\end{tabular}

a 3 - from third pass.

b 1,3 - HAZ from first pass, after three passes completed.

\subsection{Microscopy}

The same specimens that were used for the hardness tests were prepared for optical microscopy in order to observe the macro- and microstructures. The surfaces were polished to a $0.25 \mu \mathrm{m}$ finish. They were then etched by immersion with agitation in $2 \%$ Nital for $10 \mathrm{~s}$. For the macrographs a Nikon D1 $\times$ digital SLR camera was used with a Nikkor $105 \mathrm{~mm}$ macro lens. An Olympus optical microscope was used, with a Zeiss AxioCam camera and AxioVision software, for capturing the micrographs.

\section{Numerical modelling}

A two-dimensional (2-D) transient welding simulation was carried out using a commercial finite element code SYSWELD [22]. 2-D shell elements were used in the calculation. A nominal heat source power of $2500 \mathrm{~W}$ and an arc efficiency of 0.8 were assumed for each pass. Ambient temperature was $\sim 20^{\circ} \mathrm{C}$, with a pre-heat of $150{ }^{\circ} \mathrm{C}$.

Before carrying out an actual multi-pass welding simulation, a single pass 2-D transient analysis was performed for heat source fitting (HSF). More details on HSF can be found in Refs. [22,23]. Briefly, the heat power density function, as defined in Eq. (3), requires the empirical parameters $\left(a_{f}, a_{r}, b, c, Q_{f}\right.$ and $\left.Q_{r}\right)$ that need to be calibrated before it can be applied in practice. In this work, the calibration was carried out, using SYSWELD built-in HSF tools, by seeking the best possible simulation of the fusion zone (FZ). The FZ boundary was estimated by plotting the maximum temperature envelope (calculated as the maximum temperature at all nodes at any time during welding) on a contour plot with a maximum contour value of $1500{ }^{\circ} \mathrm{C}$, corresponding to the $\mathrm{FZ}$ boundary, and a minimum contour value of $850^{\circ} \mathrm{C}$.

$$
\begin{aligned}
& Q(x, y, z)=Q_{f} \exp \left(-\left(\frac{x^{2}}{a_{f}^{2}}+\frac{y^{2}}{b^{2}}+\frac{z^{2}}{c^{2}}\right)\right) \\
& Q(x, y, z)=Q_{r} \exp \left(-\left(\frac{x^{2}}{a_{r}^{2}}+\frac{y^{2}}{b^{2}}+\frac{z^{2}}{c^{2}}\right)\right)
\end{aligned}
$$

The calibrated parameters were then applied to the 2-D transient welding analysis for pass 1 . An averaged thermal cycle for the whole weld bead was exported and compiled for use by the multi-pass welding simulations. With the prescribed thermal cycle, a computation management tool called the multi-pass welding advisor (MWA), which provides automatic tools and methods to ease multi-pass welding simulations, was finally used for setting up the threepass welding simulation. The predicted thermal histories at specific locations within the one- and three-pass welded specimens were subsequently used as a basis for interpreting the influence of welding thermal cycles on the evolution of material properties.

\section{Results}

\subsection{Macrostructure}

The macrostructure of one- and three-pass weld specimens are shown in Fig. 5. The difference between the one-pass and three-pass specimens lies in the locations of the various microstructural regions. In the one-pass specimen the thermal conditions and thus the microstructures are approximately radially symmetric about the weld bead. The microstructure in the HAZ beside the weld is the same as that in the HAZ below the weld. For the three-pass specimen this is not the case.

\subsection{Microstructure}

The microstructure in the HAZ is not uniform. Closest to the fusion line there is the coarse-grained HAZ (CGHAZ) where the peak temperature experienced by the metal during welding was high enough for both austenitization and grain growth to occur. Outside this there is the fine-grained HAZ (FGHAZ) where austenitization occurred but the peak temperature was not high enough to dissolve precipitates, so there is no significant grain growth, leaving a very fine microstructure. The intercritical HAZ (ICHAZ) is outside the FGHAZ (see Ref. [12] for a more detailed discussion). In this location the peak temperature was between $A_{\mathrm{C} 1}$ and $A_{\mathrm{C} 3}$, in the ferrite-plus-austenite region. Micrographs of the different regions of the weld specimens are shown in Fig. 6 (weld metal), Fig. 7 (HAZ) and Fig. 8 (parent metal). 


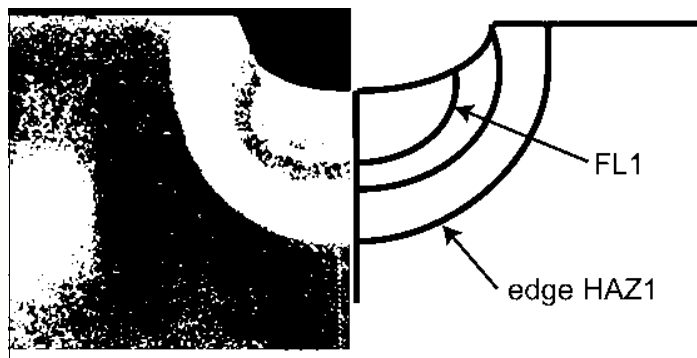

(a)

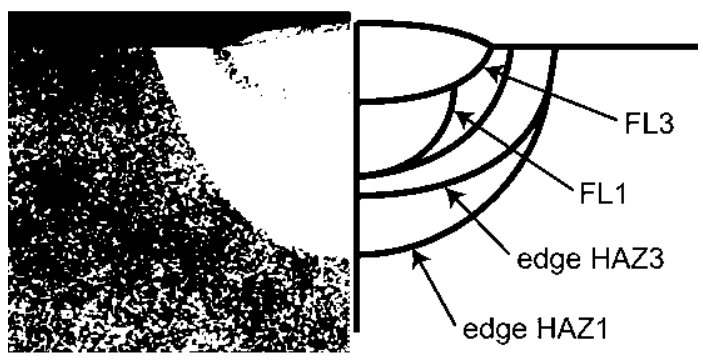

(b)

Fig. 5. Optical micrograph (left) and schematic (right) of the macrostructure of (a) the one-pass specimen and (b) the three-pass specimen. The fusion lines (FL) mark the extent of the previously molten weld metal and the heat affected zones (HAZ) for the relevant pass are also indicated.

The weld metal microstructure in the three-pass specimen (Fig. 6b) has the typical appearance of acicular ferrite, consisting of elongated ferrite grains with carbides between them in a cross-weave pattern [24]. There are also some equiaxed ferrite grains. In the one-pass specimen the weld metal structure is similar to, but finer than, the three-pass microstructure. Fine martensite may be present between the ferrite grains in the one-pass weld metal microstructure.

The comparison of the HAZ microstructures is shown in Fig. 7 where the locations are relative to the fusion line of the first pass. For example, the image of the CGHAZ in the one-pass specimen (Fig. 7a) was taken $0.5 \mathrm{~mm}$ below the fusion line for the first pass. To obtain the micrograph of the corresponding area after three passes (Fig. 7b) an image was taken $0.5 \mathrm{~mm}$ below the fusion line of the first pass in the three-pass specimen.

The expected thermal histories were obtained for specific nodes (locations) from the numerical model of the welding process (see Section 3). The nodes were chosen using the peak temperature for the first pass. The peak temperatures associated with the CGHAZ region are approximately in the range of $1500-1100{ }^{\circ} \mathrm{C}$. The equivalent temperature ranges for the FGHAZ and the ICHAZ are $1100{ }^{\circ} \mathrm{C}$ to $A_{\mathrm{C} 3}\left(790^{\circ} \mathrm{C}\right)$ and $A_{\mathrm{C} 3}\left(790^{\circ} \mathrm{C}\right)$ to $A_{\mathrm{C} 1}\left(670^{\circ} \mathrm{C}\right)$ respectively [25]. Nodes that experienced peak temperatures in the first pass of $1300{ }^{\circ} \mathrm{C}, 950{ }^{\circ} \mathrm{C}$ and $750{ }^{\circ} \mathrm{C}$ were chosen to represent the CGHAZ, FGHAZ and ICHAZ respectively. The coarse nature of the mesh used in the model meant positions relative to the fusion line could not be used alone to match the temperatures to the microstructures. The thermal paths given by the model are approximate but they give a good indication of the temperature changes driving the microstructural evolution during the three passes of the welding process.

The CGHAZ in the one-pass specimen (top left of Fig. 7) consists of bainite and some martensite. The prior austenite grain (PAG) boundaries are visible. The alteration in this microstructure after two further weld passes (the approximate thermal conditions for which are shown in Fig. 7c) is shown in Fig. 7b. The PAG boundaries are no longer discernable. The microstructure has the appearance of having been formed during the second pass, at a temperature close to $A_{\mathrm{C} 3}$. There are regions of bainitic ferrite (pale) and regions of a carbon-rich structure (darker grey); this microstructure is referred to as granular bainite [24], and is likely to contain some martensite. The third pass would have mildly tempered the microstructure from the second pass.

The fine-grained heat affected zone (FGHAZ) in the one-pass specimen (mid-left in Fig. 7) has a complex microstructure consisting of regions of densely grouped carbides (darkest areas) and the granular bainite structure. There also appear to be some small regions of martensite and/ or retained austenite. The corresponding area in the

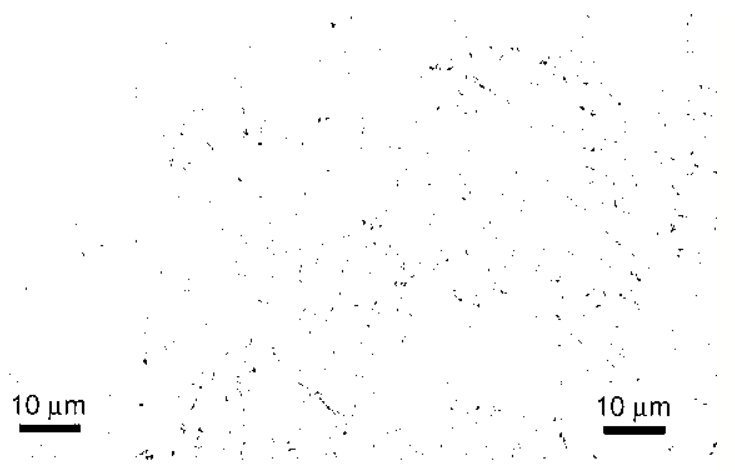

(b)

Fig. 6. Weld metal microstructure for (a) one-pass specimen and (b) three-pass specimen (final pass). 


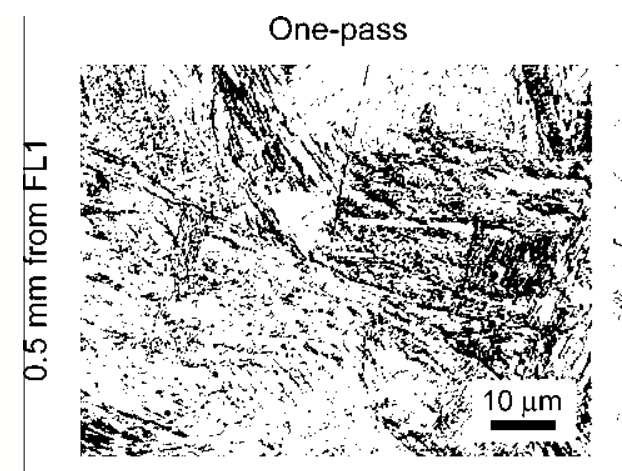

Three-pass

Thermal history
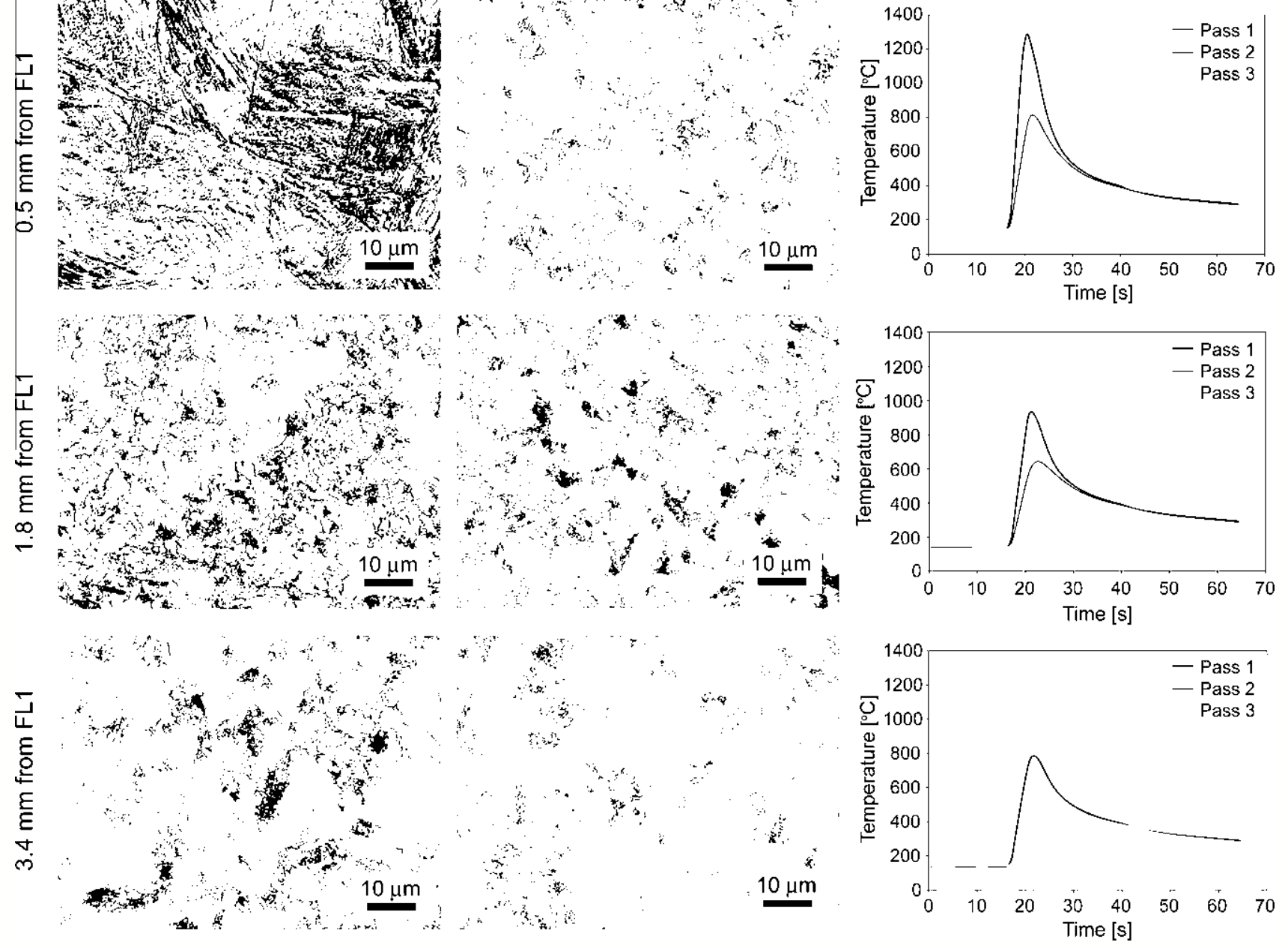

Fig. 7. Micrographs showing microstructures at different distances from the fusion line from the first pass (FL1) and their associated predicted thermal histories for the one-pass and three-pass specimens. These depths correspond to the CGHAZ1, FGHAZ1 and ICHAZ1 respectively.

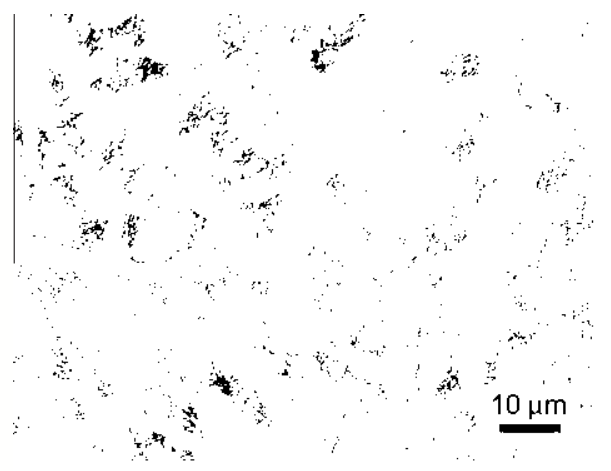

(a)

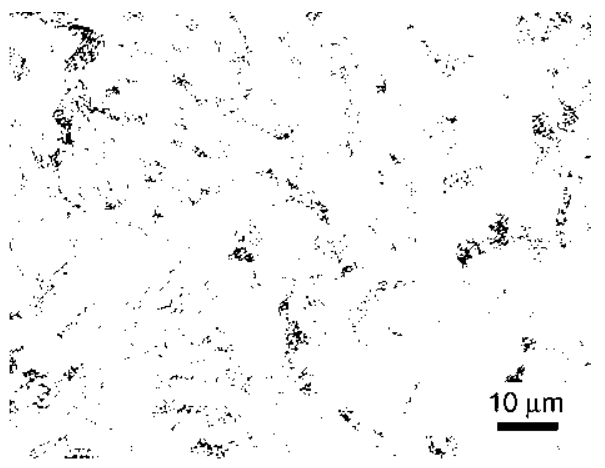

(b)

Fig. 8. Parent metal microstructure for (a) one-pass specimen and (b) three-pass specimen.

three-pass specimen has not changed in microstructure as significantly as in the case of the CGHAZ. There are areas of bainitic ferrite and carbide-dense regions. The previous carbon-rich structure has been tempered during the second pass, with carbides becoming more equiaxed and grain boundaries becoming less distinct. The third pass is unlikely to have had a significant effect.

The microstructure of the ICHAZ in the one-pass specimen (bottom left in Fig. 7) consists primarily of ferrite with smaller carbon-rich regions than in the FGHAZ. 
After two additional weld passes the microstructure has changed little. The ferrite and carbon-rich regions are still present. The carbides appear somewhat spheroidised and the grain boundaries are less distinct. This tempering effect would have occurred during the second pass with the third pass having little effect.

By definition, there are no significant differences between the microstructures of the parent metal after one pass and after three passes. The microstructure consists primarily of ferrite with regions of relatively densely packed carbides.

\subsection{Hardness}

For the single pass specimen the hardest region is the CGHAZ, just outside the fusion line. As the distance from the fusion line increases, the hardness decreases through the FGHAZ and the ICHAZ and then levels off in the parent metal. This trend is consistent in both specimens, as can be seen in Fig. 9b. The hardness in the weld metal is higher than that in the parent metal, with the one-pass weld metal being slightly harder than the three-pass weld metal. There is very slight hardening of the parent metal below the weld, shown in Fig. 9a, which is not evident to the sides of the

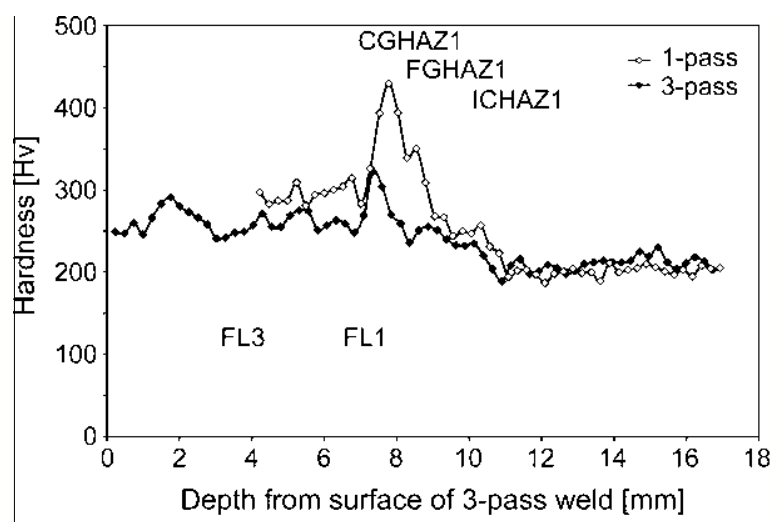

(a)

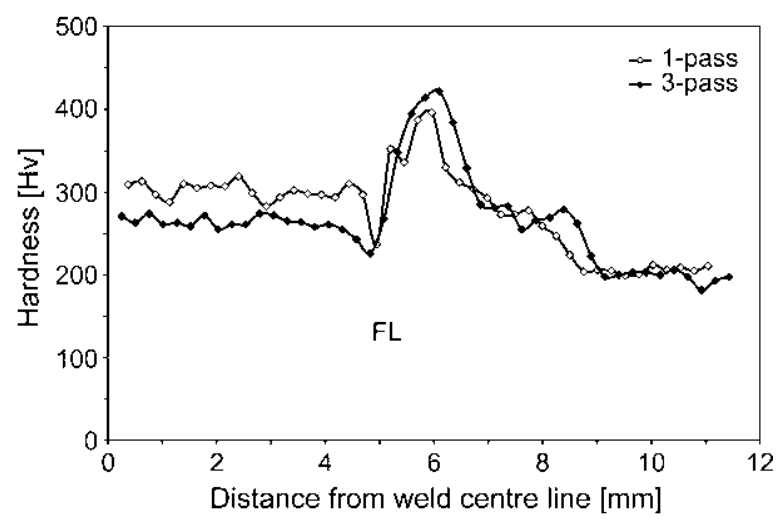

(b)

Fig. 9. Hardness of the one- and three-pass specimens measured (a) down the weld centre line and (b) parallel to the surface of the plate at depths of $4.5 \mathrm{~mm}$ (one-pass) and $2.0 \mathrm{~mm}$ (three-pass), relative to the surface of the three-pass weld. The fusion line for the third pass is indicated (FL3) as are the locations of the micrographs of the various weld regions, shown in Section 4.2 weld (Fig. 9b). These variations are discussed in terms of the weld microstructure in Section 5.1.

\subsection{Residual stresses}

Contour maps (Fig. 10) of the measured residual stresses were generated from the array of measured data, using a standard routine in MATLAB ${ }^{\mathrm{TM}}$. The pattern of the residual stress is similar in form for the two specimens; the band of peak tensile stress follows the edge of the HAZ. The magnitude of the peak tensile residual stress is slightly lower in the three-pass specimen than in the one-pass specimen but there is a significantly higher tensile stress in the weld metal in the three-pass specimen. At the back surface of the three-pass specimen there is a small area of compressive longitudinal and transverse stress while in the one-pass specimen the back surface is essentially unstressed.

\subsection{Tensile tests}

The tendency for the parent metal to undergo only limited work-hardening is evident from the slope of the stressstrain curves shown in Fig. 11. The work-hardening is more pronounced in the weld metal and in the HAZ, at least for levels of strain below 1\%. It is clear from Fig. 12 that, in both specimens, the yield stress follows the same trend as the hardness with respect to depth.

\section{Discussion}

\subsection{Microstructure, hardness and hardening}

The highest hardness is achieved in the CGHAZ after a single weld pass (Fig. 9). This region comprises a fine, aligned structure of bainite and martensite (Fig. 7, top left). This region softens after another two passes (Fig. 9a) due to its re-austenitization during the second pass, resulting in its subsequent transformation to a structure of bainitic ferrite with carbon-rich regions (Fig. 7b). The location of the CGHAZ for the first pass would correspond to the FGHAZ region in the second pass. However, the final microstructure in this location is not the same as is seen in the FGHAZ in the single pass specimen because the starting microstructure in each case was different. For example, the FGHAZ for the single pass specimen would not have reached a high enough temperature during welding to dissolve all the carbides from the parent microstructure. In contrast, in the three-pass specimen, the region corresponding to the CGHAZ for the first pass will have reached a higher temperature and thus the carbides would have been dissolved during the first pass. The low temperatures experienced by this region during the third pass would have had little effect on the microstructure.

The first-pass FGHAZ and ICHAZ regions become softer after further weld passes, although the change is not as large. The bainite in the first-pass FGHAZ, and 

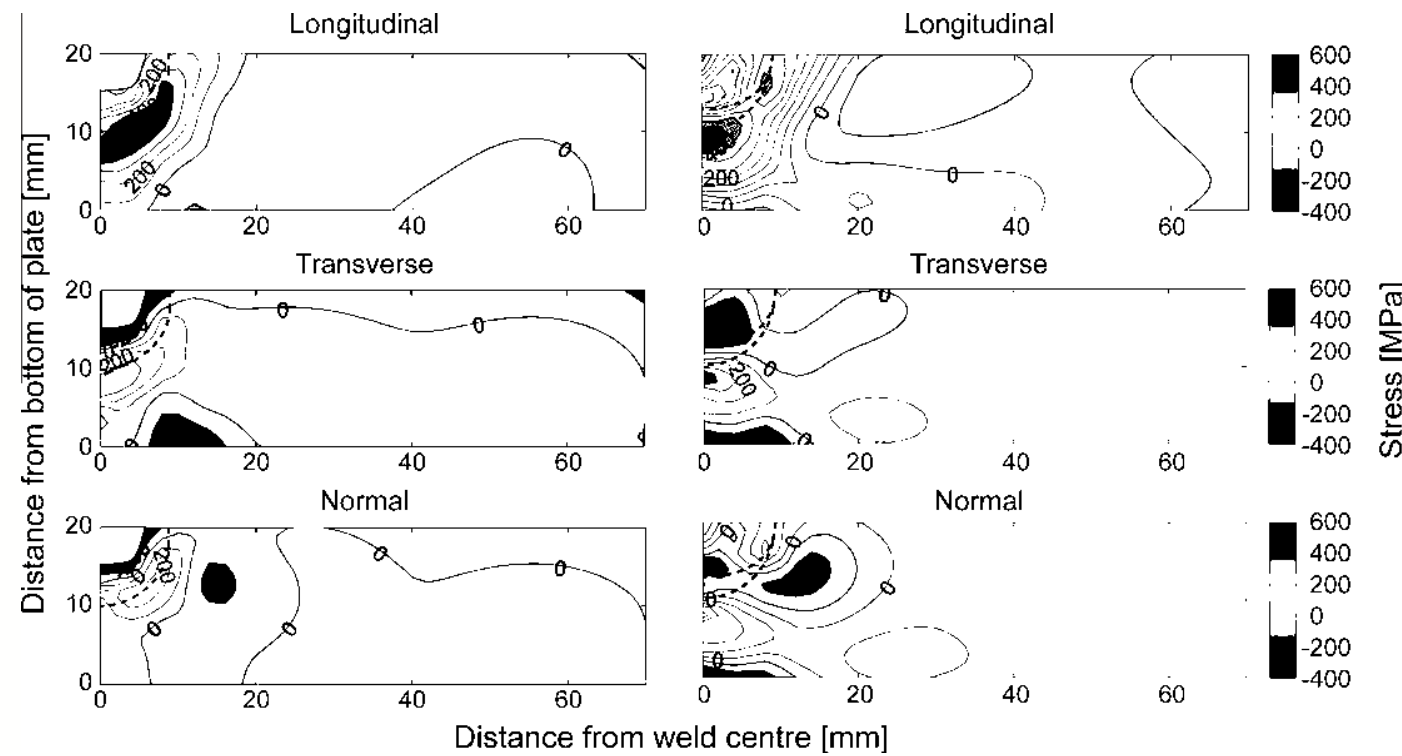

Fig. 10. Contour maps for residual stress in the one-pass specimen (left) and the three-pass specimen (right). The stresses acting in the longitudinal, transverse and normal orientations are shown for each specimen. Symmetry is assumed about the weld centreline, the left-hand border of the plots. The edge of HAZ1 is marked with a dashed line for the one-pass specimen and the edges of both HAZ3 (inner line) and HAZ1 (outer line) are marked for the three-pass specimen.

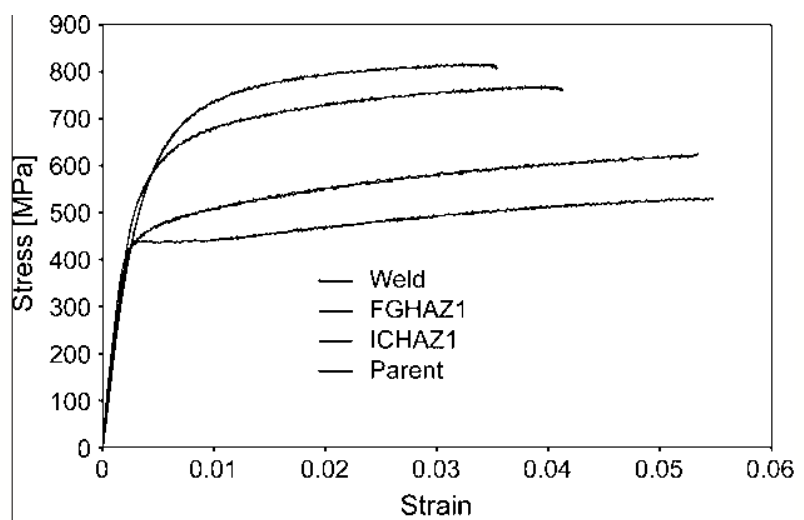

(a)

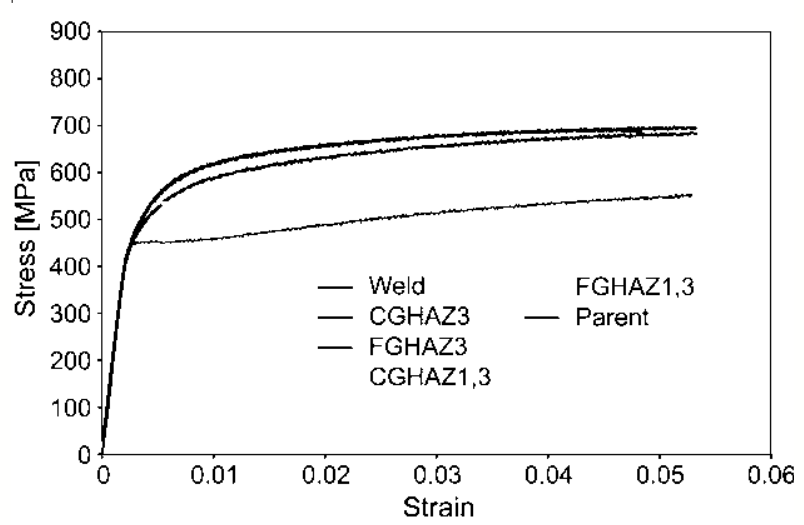

(b)

Fig. 11. Stress-strain curves for tensile specimens obtained from (a) the one-pass specimen and (b) the three-pass specimen. Parent material at depths of $12.6 \mathrm{~mm}$ and $11.2 \mathrm{~mm}$, respectively, relative to the surface of the three-pass weld. the mixed microstructure in the ICHAZ, would have been annealed during the subsequent passes without reaching temperatures high enough for austenitization to occur. The micrographs indicate that carbides in both the FGHAZ and the ICHAZ spheroidised during the second and third passes.

The hardness data show that the weld metal in the onepass specimen is harder than that in the three-pass specimen. This is likely to be related to the finer structure (Fig. 7) and a higher carbon concentration in the first weld pass. The latter results from dilution of the weld metal by the parent metal, which would be more significant in the first pass. Some dilution would also occur in the second and third passes but this effect would be smaller than in the first pass due to the smaller quantity of parent metal being melted. The lower carbon content in the weld metal will also contribute to the CGHAZ for the third weld pass having a lower hardness than the CGHAZ in the one-pass specimen. However, another significant consideration is that a CGHAZ falling within weld metal will transform to acicular ferrite on cooling, whereas the CGHAZ for the one-pass specimen falls within undiluted parent material, which transforms to a mixed bainitic-martensitic microstructure.

The slightly greater hardness in the parent metal of the three-pass specimen, when compared to the parent metal in the one-pass specimen, does not seem to result from differences in the microstructure. Indeed, there are no discernable differences in the microstructures (Fig. 8). The hardness increase is most probably a consequence of the cyclic work hardening that will have occurred as a consequence of the heterogeneous thermal strains introduced by each of the three weld passes. The stress-strain curves 


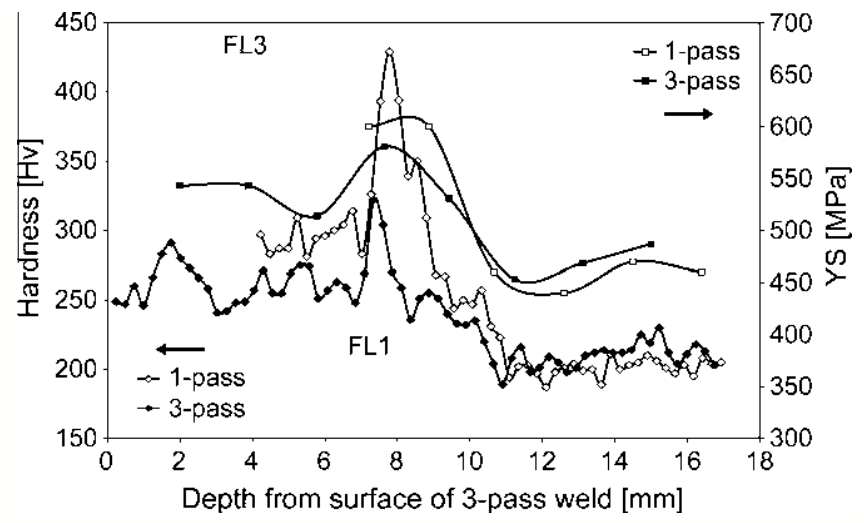

Fig. 12. Comparison of hardness and yield stress vs. depth in both specimens.

indicate that a low level of work hardening occurs in the parent metal and the slight increase in hardness is consistent with the trend (shown in Fig. 12) that the yield stress of the parent metal in the three-pass specimen is just slightly greater than that of the parent metal in the onepass specimen. This behaviour differs from that seen in austenitic stainless steel weld specimens where the work hardening due to cyclic stresses from multiple weld passes can be quite significant $[26,27]$.

\subsection{Residual stress}

Residual stresses in welds arise due to non-uniform thermal expansion and, consequently, localised irreversible strains. The irreversible strains can occur either due to plastic flow in the thermally softened metal, or due to strains associated with phase transformations. When a weld bead is deposited the resulting thermal gradients lead to greater expansion in the HAZ than in the parent metal further from the weld. The parent metal may, however, still be softened and thus plastically flow in order to accommodate the expansion of the HAZ. When the weld cools the contraction in the weld and HAZ regions will be partially resisted by the parent metal, resulting in tension in the HAZ and compression in the parent metal. However, if the weld metal and the HAZ undergo a solid-state transformation from austenite during cooling, the strains associated with the transformation can counteract the thermal contraction. This can lead to reduced tension in the weld and the HAZ. If the transformation takes place at a low enough temperature, compressive residual stresses can be generated in these regions at room temperature [16,17].

In the one-pass weld specimen the region of highest tensile residual stress is just outside the austenitised HAZ and the stress in the weld bead is low (longitudinal) or compressive (transverse). This pattern of residuals stresses agrees well with previous measurements in singlepass bead-on-plate welds [28]. In the one-pass specimen, both the weld metal and the HAZ undergo a displacive transformation from austenite during cooling (see Figs. 6a and $7 \mathrm{a}$ for micrographs). The transformation start temperature is $\sim 650^{\circ} \mathrm{C}$ for a coupon of undiluted filler metal fully austenitised at $850^{\circ} \mathrm{C}$ and subsequently cooled at $50^{\circ} \mathrm{C} \mathrm{s}^{-1}$ [28]. However, the dilution that occurs during welding will have raised the carbon content of the weld metal, leading to a lower transformation start temperature. The transformation start temperature for the parent material is $\sim 400{ }^{\circ} \mathrm{C}$, under the same conditions, and it can be even lower if faster cooling rates are experienced in the weld [28].

The work of Murakawa et al. [16] shows that as the transformation start temperature decreases, the resulting residual stress at room temperature tends from tensile to compressive, with the predicted change in sign occurring at a transformation start temperature of $\sim 400{ }^{\circ} \mathrm{C}$. In this study a preheat temperature of $150^{\circ} \mathrm{C}$ was also applied, and this will have effectively increased the transformation start temperature corresponding to this change in sign, since the application of uniform preheat reduces the scope for localised thermal contraction strains to accumulate on cooling after a transformation ceases. Thus, it can be appreciated that, with a preheat temperature of $150^{\circ} \mathrm{C}$ and dilution of the weld bead, the transformation temperatures in the one-pass specimen would have been low enough to develop compressive stresses in the weld and the reduced tensile stress in the HAZ regions. Indeed, the highest tensile stress remains in the untransformed region immediately adjacent to the HAZ boundary.

In contrast to the one-pass specimen, in the three-pass specimen the residual stresses in the final weld bead are tensile. In the three-pass weld specimen the same transformation process occurs but a lower level of dilution in the third pass leads to a higher transformation temperature. As a result the transformation temperature is above that corresponding to the change in sign, and tensile residual stresses rather than compressive stresses are developed in the third weld bead [29]. Interestingly, the effects of the transformation strain on the development of stress in the longitudinal and transverse orientations appear to differ. It is not clear whether this is a symptom of an anisotropic strain associated with the transformation itself, or whether it is related to the fact that thermal contraction misfit must be much larger in the welding direction.

Finally, the modest work-hardening that occurs in the parent metal below the weld results in slightly higher compressive residual stresses after three passes. The microstructure in the HAZ below the weld evolves from harder fine bainitic and carbide-dense structures to softer, coarser structures, leading to a slight reduction in tensile residual stress. Some martensite does form in the CGHAZ beside the final weld bead in the three-pass specimen. This lower transformation temperature, in the parent metal, leads to the region of lower residual stress between the weld bead and the outer HAZ at the surface of the three-pass specimen. 


\section{Conclusions}

One- and three-pass weld specimens have been characterised using various techniques to delineate the evolution of microstructural and residual stress that occurs during a multi-pass welding process in a ferritic weld specimen. This examination has led to several conclusions.

1. The peak hardness in the one-pass specimen is reduced by re-austenitization during the second pass and the hardness overall is lower in the three-pass specimen. The exception is in the parent material below the weld, which is slightly work-hardened by the strain cycles associated with the three weld passes.

2. The longitudinal residual stress in the weld bead in the one-pass specimen is compressive whereas the final weld bead in the three-pass specimen it is tensile. This results from an increase in transformation start temperature due to a reduced level of dilution by the parent material in the three-pass weld.

3. The peak tensile residual stresses are reduced in the three-pass specimen and they are located slightly further away from the surface of the specimen. However, the surface of the specimen to either side of the weld is under higher tensile stress in the three-pass specimen. Thus, the residual stresses in the three-pass specimen are likely to still be of concern from a weld integrity standpoint.

4. The distribution of microstructures changes from the one-pass to the three-pass specimen. The arrangement of microstructures through the HAZ is radially symmetric about the weld in the one-pass specimen but not in the three-pass specimen. For example the extensive CGHAZ region that exists all around the weld in the one-pass specimen is reduced to two small areas on either side of the weld in the three-pass specimen. This is because in the three-pass specimen the parent material to the sides of the weld experiences different cumulative thermal conditions than that below the weld. This difference in distribution is reflected in the macrostructure, the hardness curves, and the residual stress maps.

5. In this work we have focused on a three-pass specimen in which all passes were deposited on the weld centreline, and for which the transformation temperature of the undiluted filler metal was higher than that for the parent material. Further work is in progress in which the authors are investigating the development of stress in multi-pass welds made with a low transformation temperature filler material. Further work is also required to assess the development of residual stress and material properties in multi-pass steel welds for which the deposition sequence is asymmetric.

\section{Acknowledgements}

The authors would like to acknowledge Forschungsneutronenquelle Heinz Maier-Leibnitz (FRM II) for beam time granted. A.F.M., J.A.F., H.D. and M.T. are also grateful for support from Rolls-Royce Marine, in particular for manufacturing the weld specimens.

\section{References}

[1] Radaj D. Heat effects of welding - temperature field, residual stress, distortion. Berlin: Springer-Verlag; 1992.

[2] Read DT. Eng Fracture Mech 1989;32:147.

[3] Withers PJ. Rep Progress Phys 2007;70:2211.

[4] Turski M, Bouchard PJ, Steuwer A, Withers PJ. Acta Mater 2008;56:3598.

[5] R6 revision 4 - assessment of the integrity of structures containing defects. British Energy Generation Ltd.; 2004.

[6] Turski M, Smith MC, Bouchard PJ, Edwards L, Withers PJ. J Pressure Vessel Technol 2009;131:061406.

[7] O'Dowd NP, Nikbin KM, Wimpory RC, Biglari FR, O'Donnell MP. J Pressure Vessel Technol 2008;130:041403.

[8] Smith MC, Smith AC. Int J Pressure Vessels Piping 2009;86:79.

[9] Smith MC, Nadri B, Smith AC, Carr DG, Bendeich PJ, Edwards L. In: Proc ASME pressure vessels piping conf 2009, vol. 6AB; 2009. p. 303.

[10] Muransky O, Hamelin CJ, Smith MC, Bendeich PJ, Edwards L. Comput Mater Sci 2012;54:125.

[11] Francis JA, Mark AF, Turski M, Bate SK, Hofmann M, Withers PJ. In: Proc ASME pressure vessels piping conf 2010, vol. 6AB; 2010. p. 1415.

[12] Francis JA, Bhadeshia HKDH, Withers PJ. Mater Sci Technol 2007;23:1009.

[13] Bhadeshia HKDH. Mater Sci Eng A 2004;378:34.

[14] Ohta A, Suzuki N, Maeda Y, Hiraoka K, Nakamura T. Int J Fatigue 1999;21:S113.

[15] Wang WX, Huo LX, Zhang YF, Wang DP, Jing HY. J Mater Sci Technol 2002;18:527.

[16] Murakawa H, Beres M, Davies CM, Rashed S, Vega A, Tsunori M, Nikbin KM, Dye D. Sci Technol Welding Joining 2010;15:393.

[17] Moat RJ, Stone HJ, Shirzadi AA, Francis JA, Kundu S, Mark AF, Bhadeshia HKDH, Karlsson L, Withers PJ. Sci Technol Welding Joining 2011;16:279.

[18] Cho H, Kim IS. Mater Sci Forum 2005;475-479:4121.

[19] Withers PJ, Preuss M, Steuwer A, Pang JWL. J Appl Crystallogr 2007;40:891.

[20] Hutchings MT, Withers PJ, Holden TM, Lorentzen T. introduction to the characterization of residual stress by neutron diffraction. London: Taylor and Francis; 2005.

[21] Daymond MR, Priesmeyer HG. Acta Mater 2002;50:1613.

[22] ESI-Group. SYSWELD. Theory manuals. Oxford: ESI UK; 2009.

[23] Dai H, Francis JA, Withers PJ. Mater Sci Technol 2010;26:940.

[24] Bhadeshia HKDH. Bainite in steels. London: Institute of Materials, Minerals and Mining; 2001.

[25] Francis JA, Dai H, Withers PJ. Unpublished results.

[26] Skelton RP, Goodall IW, Webster GA, Spindler MW. Int J Pressure Vessels Piping 2003;80:441.

[27] Bhanu Sankara K, Valsan M, Mannan SL. Mat Sci Eng A 1990;130:67

[28] Francis JA, Turski M, Withers PJ. Mater Sci Technol 2009;25:325.

[29] Dai H, Francis JA, Stone HJ, Bhadeshia HKDH, Withers PJ. Metal Mater Trans A 2008;39A:3070. 